\title{
A NEW GUANIDINE DERIVATIVE: DISSOCIATION OF THE ADRENERGIC NEURON BLOCKING ACTIVITY FROM LOCAL ANESTHETIC ACTIVITY
}

\author{
Yoshimi MISU, Hiroaki NISHIO*, Teruko HOSOTANI \\ and Sachiyuki HAMANO** \\ Departmen of Phamacology, Fuculty of Phamacinteal Scicines, \\ Kyoto University, Kyoto 606, Japan \\ Accepted February 18, 1976
}

\begin{abstract}
Ffficels of 4-7-exo-methylene-hexahydroisoindoline-ethyl-guanidine hemisulfate (No. 865-123), a new guanidine derivative, on adrenergic neurons and its local anesthetic activity were investigated in comparison with guanethidine. Both derivatives produced in a dose-dependent manner a progressive irreversible reduction of positive chronotropic and contractile responses to postganglionic sympathetic nerve stimulation in isolated rabbit atria. The time course of the reduction by No. 865-123 was somewhat slower. In dogs administered both agents, the pressor response to carotid occlusion was reduced and that to exogenous noradrenaline was potentiated with a slight decrease in blood pressure. Noradrenaline stores in the heart and spleen of rats were also depleted to a similar extent. In the guinea pig weal method, guanethidine acted as a potent local anesthetic with a slow onset and a prolonged action as compared to procaine. Vo. 865-123 revealed no more anesthetic activity than did saline. It is unlikely that the local anesthetic activity of the guanidine derivatives contributes to the adrenergic neuron blocking activity.
\end{abstract}

Since bretylium and guancthidine were found to be effective in the treatment of hypertension (1-3), a large number of adrenergic nouron blockers has been synthesized and pharmacologically investigated (4-7). The mechanism by which these drugs prevent the release of noradrenaline at adrenergic nerve endings is unknown. It has been suggested, however, that the mechanism related to bretylium and guanethidine could be explained by a selective local anesthesia of adrenergic nerve endings in combination with the high accumulation of the blockers in these sites $(4,8,9)$. On the other hand, Kubo and Misu (10) found that in isolated rabbit hearts, the adrenergic neuron blockade induced by guanethidine was restored by subsequent perfusion with a low sodium solution and accentuated with a high sodium solution. The present work revealed that a newly synthesized derivative produces a marked adrenergic ncuron blocking activity which may he dissociated from its local anesthetic activity.

\section{MATERIALS AND METHODS}

The isolated sympathetic atrial preparation of rabbits was used to determine adrenergic

* Present address: Department of Pharmacology, hastitute of Pharmaceutical Sciences,

H liroshima University School of Medicine, Hiroshima, Japan

** Present address: Chemical Laboratory, Eisai Co., Ltd., Tokyo, Japan 
neuron blocking aclivity. Rabbils of either sex, 1.7 to $2.1 \mathrm{~kg}$, were anesthetized with sodium pentobarbital $50 \mathrm{mg} / \mathrm{kg}$ injected i.p. The chest was opened under artificial respiration. The atrium with bilateral sympathetic trunks was isolated and prepared as described previously (11). The trunks were ligated at the extreme upper thoracic level. The ligature and nerve were passed by a needle into the channel of ring electrodes similar to those described by Garry and Gillespic (12) through a rubber diaphragm, which partitioned both plastic cells covering a pair loops of silver wire, and were held between a plastic cap and the casing of the proximal cell filled with oxygenated nedium. The entire preparation was suspended in a muscle chamber containing Krebs bicarbonate solution, bubbled with $5 \% \mathrm{CO}_{2}$ in oxygen, having the following composition expressed in $\mathrm{mM}: \mathrm{NaCl} 118.4 ; \mathrm{KCl} 4.7 ; \mathrm{CaCl}_{2}$ 2.5; $\mathrm{MgCl}_{2} 1.18 ; \mathrm{NaHCO}_{3} 25 ; \mathrm{KH}_{2} \mathrm{PO}_{4} 1.2 ;$ and glucose 11.1. The final $\mathrm{pH}$ was 7.5. The temp. was maintained at $30^{\circ} \mathrm{C}$. Atrial spontaneous contraction was recorded on a smoked paper with a semi-isotonic lever. The nerve was stimulated with an electronic stimulator MSE-3 (Nihon Kohden) for $30 \mathrm{sec}$ with supramaximal rectangular pulses of $1 \mathrm{msec}$ duration, a frequency of $30 \mathrm{~Hz}$ and at intervals of 30 or $45 \mathrm{~min}$. The nerve, the stimulation of which produced pasitive chronotropic and contractile responses of the rabbit heart, was postganglionic (13). Atrial beats/min were counted before and every 1 min after the start of nerve stimulation.

Mongrel dogs of either sex, 6.8 to $14.2 \mathrm{~kg}$, were used for the observation of arterial mean blood pressure. The animals were anesthetized with an i.p. injection of amobarbital sodium 80 to $120 \mathrm{mg} / \mathrm{kg}$. Arterial blood pressure was recorded, through a cannula inserted into the right femoral artery, using a Motor-driven Kymograph (Kyushu University Type, Nogami) via a mercury manometer. Respiration was recorded via a tambour connected to a tracheal cannula. Bilateral common carotid arterics were exposed for the observation of occlusion pressor reflex. Drugs were injected into the Ieft femoral vein.

The content of endogenous noradrenaline in the heart and spleen of rats of either sex, 250 to $300 \mathrm{~g}$, was measured fluorometrically by the method described by Bertler et al. (14). Recovery was approx. $70 \%$.

Local anesthetic activity was investigated using the method described by Bülbring and Wajda (15). The loss of sensation in the skin of the guinea pig of either sex, 400 to $600 \mathrm{~g}$, following an intradermal injection of a local anesthetic was assessed. The flanks of the animal were depilated on the day before the tests. The injection volume was $0.25 \mathrm{ml}$. Each of 2 concentrations of the drug as well as normal saline was injected into 2 sites on each of 3 guinea pigs. Solutions were injected in randam order. Each injection site was tested by pricking 6 times using a finc stainless wire. The degree of anesthesia induced by each concentration of the drugs was assessed by noting the number of times the animals failed to respond out of a total of 36 trials.

The drugs used were guanethidine sulfate (Ciba-Geigy), bretylium tosylate (Wellcome), procaine hydrochloride (Fujisawa), dl-noradrenaline hydrochloride (Sankyo) and 4-7-exomethylene-hexahydroisoindoline-ethyl-guanidine hemisulfate (Eisai), which is referred to as No. 865-123. This derivative is a white crystalline powder with a molecular weight of 
271 and is soluble as a $1 \%$ solution in water at the usual pH and temp.. Fig. 1 demonstrates the structural formula of No. 865-123. All drugs were dissolved in

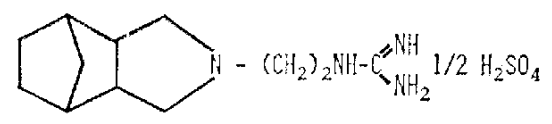

FiG. 1. Structural formula of No. 865-123.

saline. Student's $t$-test was used to evaluate data. $N$ indicates the number of estimations.

\section{RESULTS}

Effects of guanethidine and No. 865-123 on altenergic neurons in rabbit atria

In Fig. 2 and Table 1, the atrial rate in rabbit atria at the start was $78 \div 8 / \mathrm{min}(\mathrm{n}-7)$. The $30 \mathrm{sec}$ stimulation of the sympathetic nerve produced marked increases in the atrial beats and contractile force. Peak positive chronotropic and contractile responses were observed

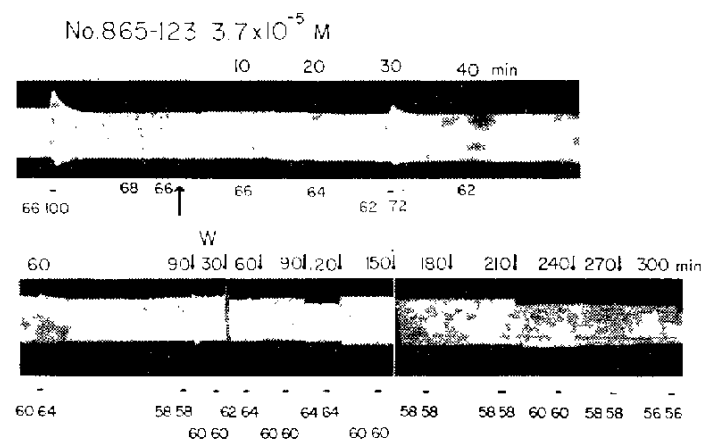

FiG. 2. Typical effects of No. 865-123 on adrenergic neurons in isolated rabbit atria. Sympathetic nerve was stimulated for $30 \mathrm{sec}$ at horizontal bars. The drug was added at upward arrow. W: washing at downward arrows. Numbers over the trace indicate time after the drug addition and after the lst overflowing. Numbers under the trace represent atrial beats:min before and at the peak of responses to nerve stimulation.

TABLE 1. Time course of effects of guanethidine and No. 865-123 on adrenergic neurons in isolated rabbit atria

\begin{tabular}{|c|c|c|c|c|}
\hline $\begin{array}{l}\text { Drug } \\
\text { (M) }\end{array}$ & $N$ & $\begin{array}{l}\text { Time after } \\
\text { addition } \\
\text { (min) }\end{array}$ & $\begin{array}{c}\text { Positive chronotropic } \\
\text { responses } \\
(\%)\end{array}$ & $\begin{array}{c}\text { Positive contractile } \\
\text { responses } \\
(\%)\end{array}$ \\
\hline$(121)-\ldots$ & & Before & 100 & 100 \\
\hline Guanethidine & 3 & 30 & $17.0 \pm 14.4^{*}$ & $12.5 \pm 3.6$ \\
\hline \multirow[t]{2}{*}{$2.0 \times 10^{-5}$} & & 60 & 0 & 0 \\
\hline & & Before & 100 & 100 \\
\hline No. $865-123$ & 4 & 30 & $56.3+15.8$ & $40.2 \pm 4.6$ \\
\hline \multirow[t]{3}{*}{$3.7 \times 10^{-5}$} & & 60 & $34.0 \pm 17.3$ & $22.9 \pm 4.9$ \\
\hline & & 90 & $15.3 \pm 10.5$ & $9.21: 3.8$ \\
\hline & & 120 & 4.2 .1 .4 .2 & $1.7 \dashv 1.7$ \\
\hline
\end{tabular}

The drug was added $15 \mathrm{~min}$ after control nerve stimulation. Thereafter, the nerve was stimulated at intervals of $30 \mathrm{~min}$. Peak positive responses to nerve stimulation after the drug addition are expressed as a \% of control responses. *: Mean $t$-standard error. 
1 to 2 min after the start of stimulation and perent increases in both paraneters were 60.7 1. 6.4 and 69.8 . 13.2. These positive responses returned to normal 10 to $15 \mathrm{~min}$ after stimulation. In untreated preparations, atrial beats reached a slightly lower level than seen at the start 30 min after stimulation (16). In the present experiment, a drug was added to the bath 15 min after control stimulation. Guanethidine $2 \times 10^{-5} \mathrm{M}$ produced a slight and prolonged sympathomimetic action. The percent increase in atrial beats was $9.3+1.6,8.2 \pm 1.9$ and $7.6 \pm 2.2$ of those before the addition, 10,20 and $30 \mathrm{~min}$ after the addition, respectively. On the other hand, No. 865-123 $3.7 \times 10^{-5} \mathrm{M}$ itself produced no sympathomimetic action as demonstrated in Fig. 2. The percent change of atrial beats was $-0.1 \pm 1.5,-3.5 \pm 1.0$ and $-5.9-0.7,10,20$ and $30 \mathrm{~min}$ after the addition. In one atrium, in which nerve stimulation was not given, there were no modifications whatever of the atrial beats and contractile force until 90 min after the addition of No. 865-123 $3.7 \times 10^{-5} \mathrm{M}$. The rate of rise and the peak of positive responses to nerve stimulation were progressively reduced by the drug. The duration of responses was shortened. Positive responses were abolished $90 \mathrm{~min}$ after the addition. The transmission blockade was irreversible by repetitive overflowing with fresh solution until at least $5 \mathrm{hr}$ after the 1 st washing. Out of 4 preparations summarized in Table 1 , the transmission was abolished in 2 atria $90 \mathrm{~min}$ after and in one $120 \mathrm{~min}$ after the addition of No. $865-1233.7 \times 10^{-5} \mathrm{M}$. Guanethidine $2 \times 10^{-5} \mathrm{M}$ markedly reduced atrial peak positive chronotropic and contractile responses to nerve stimulation and abolished them $60 \mathrm{~min}$ after the addition. The duration of positive responses was also markedly shortened. The blocked transmission was not restored by repetitive washing until $5 \mathrm{hr}$ after the 1 st overflowing.

Fig. 3 demonstrates the dose-response relationship of blocking effects of guanethidine $(n=6)$ and No. 865-123 $(n-7)$ on adrenergic transmission in rabbit atria. Each point re-

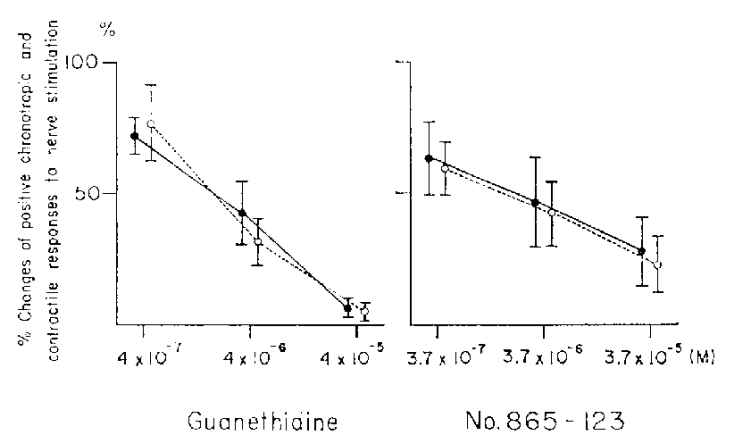

FIG. 3. Dose response relationship of effects of guanethidine and No. 865-123 on adrenergic neurons in isolated rabbit atria. Sympathetic nerve was stimulated 4 times in each preparation at intervals of $45 \mathrm{~min}$. The drug was added in the order from low to high dose 15 min after the preceding stimulation. The drug solution was allowed 10 overflow with fresh solution 5 min after stimulation. Peak positive chronotropic (solid line) and contractile (dotted line) responses to nerve stimulation after the addition of each concentration of drugs are expressed as a $\%$ of those to the lst stimulation. Vertical bars show standard errors. 
presents a " change of peak positive chronotropic (solid line) and contractile (dotted line) responses to nerve stimulation $30 \mathrm{~min}$ after the addition of each concentration of drugs. The decreases in positive responses were dependent on the dose of guanethidine as well as No. 865-123. The slope of the dose response curve of No. 865-123, however, was slightly flat as compared to that of guanethidine.

\section{Acute effects of guanethidine and No. 865-123 on blood pressure in normotensive dogs}

Fig. 4-A demonstrates a typical triphasic effect of guanethidine $15 \mathrm{mg} / \mathrm{kg}$ on blood pressure and guanethidine-induced modifications of pressor responses to noradrenaline and to the $30 \mathrm{sec}$ occlusion of bilateral common carotid arteries in dogs. Before the injection of guanethidine, noradrenaline $3 \mathrm{r} / \mathrm{kg}$ produced a pressor response of $50 \mathrm{mmHg}$ at a peak level, and this response returned to normal 3 to 5 min after the injection. Carotid occlusion induced the pressor response of $20 \mathrm{mmHg}$ and a recovery was observed within $2 \mathrm{~min}$. The injection of guanethidine $7.5 \mathrm{mg} / \mathrm{kg}$ was given twice at intervals of $15 \mathrm{~min}$ in order to avoid a lethal action as a result of its immediate rapid depressor effect. Blood pressure fell abruptly by approx. $40 \mathrm{mmHg} 1 \mathrm{~min}$ after the injection, and the hypertension which followed reached a high level of approx. $50 \mathrm{mmHg} 5$ to $6 \mathrm{~min}$ after the injection, and then decreased gradually. The 2nd injection of the drug $7.5 \mathrm{mg} / \mathrm{kg}$ produced a similar but slightly suppressed blood pressure response compared to that of the 1st injection. Hypertension persisted for 2 to

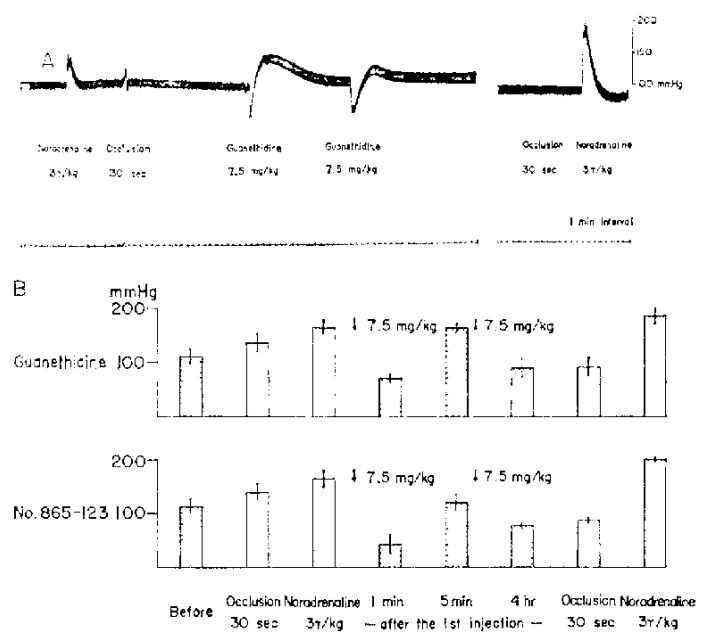

FIG. 4. Effects of guanethidine and No. 865-123 on blood pressure in normotensive dogs. A shows a typical effect of guanethidine. Occlusion was performed at the bilateral common carotid arteries. Guanethidine $7.5 \mathrm{mg} / \mathrm{kg}$ was injected twice at $15 \mathrm{~min}$ intervals. The riglit part of the trace shows blood pressure $4 \mathrm{hr}$ after the lst injection. B shows summarized effects of guanethidine and No. 865-123 observed in the same experimental design as that in A. Each column represents the peak level of changes in mean blood pressure induced by drugs or occlusion. Shaded columns demonstrate the level of blood pressure before, $1 \mathrm{~min}, 5 \mathrm{~min}$ and $4 \mathrm{hr}$ after the Ist injection of guanidine derivatives. Vertical bars indicate standard errors. 
$3 \mathrm{hr}$ and then blood pressure reached a level of $20 \mathrm{mml}$ Ig lower than the control level $4 \mathrm{hr}$ after the 1 st injection. At this time, the pressor response to occlusion was completely blocked, but that to noradrenaline was markedly potentiated. The duration of the noradrenaline action was also prolonged. Fig. 4-B shows summarized data of guanethidine $(n=4)$ and No. 865 $123(n=3)$ obtained in the same experimental design as that of the upper trace.

As demonstrated in lower shaded columns, No. $865-12315 \mathrm{mg} / \mathrm{kg}$ produced a blood pressure pattern similar to that induced by guanethidine. The initial depressor response, however, was slightly marked and the following pressor response was less prominent compared to that of guanethidine. The blood pressure level decreased by approx. $30 \mathrm{mmHg}$, $4 \mathrm{hr}$ after the injection. No. 865-123 reduced the pressor response to carotid occlusion and prominently potentiated that to noradrenaline. The amplitude of respiratory movement after the injection of guanethidine as well as $\mathrm{N}_{0} .865-123$ was slightly decreased and increased at a time corresponding to the initial depressor and the following pressor phase of blood pressure, and then gradually was restored.

Effects of guanethidine and No. 865-123 on the content of endogenous noradrenaline of the heart and spleen of rats

As demonstrated in Table 2, guanethidine $15 \mathrm{mg} / \mathrm{kg}$ as well as the same dose of No. 865-123 significantly depleted the noradrenaline content of the heart and spleen to a $1 / 3$ to $1 / 2$ of control at $24 \mathrm{hr}$ after the i,p. injection.

TABLE 2. Effects of guanethidine and No. 865-123 on the content of endogenous noradrenaline of the heart and spleen of rats $24 \mathrm{hr}$ after the i.p. injection

\begin{tabular}{lrcc}
\hline \multicolumn{1}{c}{ Drug } & $N$ & \multicolumn{2}{c}{ Noradrenaline $(\mu \mathrm{g} / \mathrm{g}$ tissue $)$} \\
$15 \mathrm{mg} / \mathrm{kg}$ i.p. & & Heart & Spleen \\
\cline { 1 - 1 } Control & 18 & $0.90 \pm 0.06^{*}$ & $1.05 \pm 0.06$ \\
Guanethidine & 9 & $0.33 \pm 0.03^{* *}$ & $0.39 \pm 0.03^{* *}$ \\
No. $865-123$ & 9 & $0.35-0.05^{* *}$ & $0.52 \pm 0.06^{* * *}$ \\
\hline
\end{tabular}

*: Mean \pm standard error.

**: Value is significant from control, $\mathbf{P}<0.01$.

Local anesthetic effects of guanethidine and No. 865-123

As shown in Fig. 5-A, the peak anesthesia produced by $1,1.25$ and $2.5 \%$ procaine solution was obtained $10 \mathrm{~min}$ after the injection and a complete recovery was observed 30 to $60 \mathrm{~min}$ after the injection. On the other hand, the peak induced by $0.25,0.5$ and $1 \%$ solution of bretylium was observed 20 to $35 \mathrm{~min}$ after the injection and the recovery was obtained 55 to 85 min after the injection (Fig. 5-B).

As demonstrated in Fig. 4-C, the onset of anesthesia produced by guanethidine was slower, the peak action was much more potent and the duration of action was much more prolonged than that of procaine. The anesthetic effect of guanethidine was thus dosedependent. On the other hand, No. $865-123$ produced practically no anesthesia in a pre- 


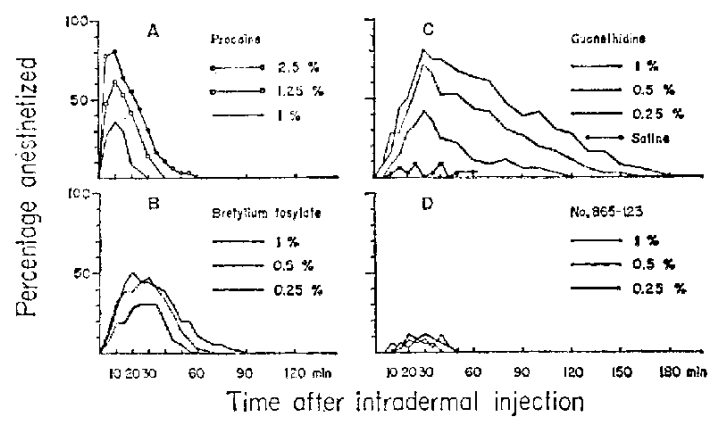

FiG. 5. Local anesthetic effects of intradermal injection of procaine, bretylium, guanethidine and No, 865-123 in guinea pigs. Each point represents the number of times 3 guinea pigs failed to respond the pricking in the injected area, out of a total of 36 trials, expressed as a $\%$.

liminary test. Data shown in Fig. 5-D and those for saline in Fig. 5-C were obtained by the method of a blind technique. The peak number of loss of sensation to pricking injected sites induced by each concentration of the drug was 4 out of the total of 36 trials and that following saline injection was 3 out of 36 tests.

\section{DISCUSSION}

Great similarities between No. 865-123 and guanethidine were evident regarding actions on the isolated sympathetically innervated atria of rabbits, the blood pressure of normotensive dogs and the endogenous noradrenaline content of the heart and spleen of rats. Both guanidine derivatives produced a progressive reduction of atrial positive chronotropic and contractile responses to sympathetic nerve stimulation. The time course and the slope of the dose response curve of the reduction induced by No. 865-123 was slightly slower and somewhat less sharp than that by guanethidine. The transmission blockade produced by the 2 drugs was very persistent even by repetitive washing. This blockade in vitro was consistent with the blockade or reduction of the pressor reflex response to the occlusion of common carotid arteries in dogs. On the other hand, both agents markedly potentiated the pressor response to exogenously injected noradrenaline at a time when blood pressure was slightly reduced. This potentiation induced by No. $865-123$ appears to be mainly due to the same mechanism as that observed with guanethidine for the inhibition of noradrenaline uptake into adrenergic nerve endings (4). Furthermore, these agents depleted noradrenaline stores in the heart and spleen of rats, to a similar extent. Our results demonstrate that No. 865-123 has a highly potent affinity for adrenergic nerve endings as does guanethidine. Differing from guanethidine however, No. 865-123 produced no sympathomimetic actions in rabbit atria and little elevation of blood pressure above the control level in dogs within the concentrations used. It seems unlikely that the sympathomimetic action of guanethidine contributes to its adrenergic neuron blocking activity.

It has been stated that drugs with adrenergic neuron blocking activity consist of 3 units; a highly basic group, such as quaternary ammonium, guanidine or amidoxime, joined 
through a connecting chain to a ring structure which contains a second weaker basic group $(4,5)$. The structure of No. 865-123 conformed to this pattern. The results of the present experiment support the findings presented by Schlittler et al. (5) that derivatives with an unsubstituted ethylene linkage were pharmacologically highly active, and the findings demonstrated by Costa et al. (6) that compounds having the guanidine group separated from a benzene ring by 2 carbon atoms depleted the content of catecholamines in rat hearts.

Bretylium and guanethidine were confirmed, using the guinea pig weal technique, to act as potent local anesthetics having a slow onset of action and a prolonged action in comparison with procaine, as presented by Boyd et al. (17) and Rand and Wilson (7). On the other hand, the local anesthetic activity of No. 865-123 was not distinguishable from that following the saline injection within the concentrations used. In various sympathetically innervated organs $(7,10)$, the dosage of procaine required to block adrenergic transmission was much higher than that of guanethidine, the onset of the blockade was almost immediate and the recovery was also rapid after removal of the drug from the preparation. No. 865-123 proved to have irreversible adrenergic neuron blocking activity, had a slow time course and lacked local anesthetic activity. The possibility remains however, that adrenergic nerve endings accumulate a concentration of bretylium or guanethidine sufficient to act as a local anesthetic at these sites $(4,8,9)$. If this hypothesis were extrapolated to the mechanism of adrenergic neuron blocking activity of No. 865-123, the rate or amount of the accumulation of this guanidine derivative should be much higher, possibly 10 to nearly 100 times higher than that of guanethidine.

In addition, Kubo and Misu (10) demonstrated that guanethidine-induced blockade of adrenergic transmission in rabbit hearts was restored when nerves were stimulated during the subsequent perfusion with a low sodium solution and accentuated with a high sodium solution. In isolated atria of rabbits, utilized as a membrane model, guanethidine clearly prolonged the time of automatism arrest induced by exposure to a sodium deficient medium (18), and increased the maximum rate of rise of action potentials without hyperpolarization (19). Baba and Smith (20) demonstrated that guanethidine increased potential differences and increased ${ }^{24} \mathrm{Na}$-influx in the frog skin membrane. Guanethidine certainly has these paradoxical actions $(10,18-20)$, and such can never be attributed to the membrane stabilizing action of local anesthetics (21-24). It has been emphasized that guanethidine increases the permeability of the adrenergic nerve ending membrane to sodium ions, thereby, leading to adrenergic neuron blockadic (10). From the results of the present experiments, it seems unlikely that the local anesthetic activity of guanidine derivatives contributes to their adrenergic neuron blocking activity.

Acknowledgements: Thanks are due to Prof. H. Takagi for pertinent advice and Mr. H. Nishinura for technical assistance.

\section{REFERENCES}

1) Boura, A.L.A., Green, A.F., McCoubrey, A., Laurence, D.R., Moulton, R. And RosenHEIM, M.L.: Lancet 2, 17 (1959) 
2) PhGE, I.H. A.\D DusLan, H.P.: J. Am. Med. Ass. 170, 1265 (1959)

3) Maxwelt., R.A., Piummer, A.J., Schilidfr, F., Povalski, H. and Daniel, A.I.: J. Pharmacol. exp. Ther. 128, $22(1960)$

4) Boura, A.L.A. and Grefn, A.F.: A. Re . Pharmacol. 5, 183 (1965)

5) Schlittler, E., Druley, J. and Marxir, A.: Progress in Drug Research 4, p. 341, Edited by JUCKLR, E., BirkHẌUSER, Basel (1962)

(1) Costa, E., Kuntzmax, R., Gr.ssa, G.L. and Brodie, B. B.: Life Sici. 3, 75 (1962)

7) Rand, M.J. and Wilson, J.: Europ. J. Pharmacol. 1, 200 (1967)

8) Haeusler, G. Haffety, W. nnd Hulrliman, A.: Arch. exp. Path. Pharmacol. 265, 260 (1969)

9) Haeusler, G., Thoenen, H., Haefely, W. And Huerlmani, A.; Helv. physiol. pharmacol. Acta 26, CR 352 (1968)

10) Kubo, T. and Misu, Y.: Japan. J. Pharmacol. 24, 307 (1974)

11) Misu, Y. And KiRprikar, S.M.: J. Pharmacol. exp. Ther. 163, 330 (1968)

12) Garky, R.C. ant Gil.tFselt, J.S.: J. Physiol. 128, 557 (1955)

13) Mist, Y. and KuBo, 'T.: Japan. J. Pharmacol. 22, 359 (1972)

14) Bertllik, A., Carlsson, A. And Rosengrev, E.: Acta physiol. scand. 44, 273 (1958)

15) Bielbring, L. ANd Wajda, I.: J. Pharmacol exp. Ther. 85, 78 (1945)

16) Misu, Y., Kurdisil, Y. and Takagi, H.: Japan. J. Pharmacol. 23, 891 (1973)

17) Boyd, H., Cianig, V. ANd Rand, M.J.: Archs int. Pharmacodyn. Thér. 131, 10 (1961)

18) Misu, Y. And Nishio, H.: Iapan. J. Pharmacol. 23, 740 (1973)

19) Misu, Y.: Japan. J. Pharmacol. 24, Suppl. 132p (1974)

20) Baba, W.I. And Smith, A.J.: Q. Jl. exp. Physiol. Cog. Med. Sci. 49, 194 (1964)

21) Condouris, G.A.: J. Pharmacol. exp. Ther. 131, 243 (1961)

22) Shanes, A.M.: Pharmacol. Rer. 10, 59 (1958)

23) Ritchie, J.M. Avd Grhagald, P.: A. Ret. Pharmacol. 6. 405 (1966)

24) Trautwein, W.: Pharmacol. Rev. 15, 277 (1963) 